and struggles.

Mr Watene had a family but apparently no one at Oakley thought of contacting them.

Morale is sustained in part by working within a known framework. Doctors and nurses need clear-cut procedures which define the limits of each person's responsibility and do not impose what may prove an unfair or impossible burden on a relatively inexperienced or untrained person. The decision to seclude should never be just one nurse's thought. Drugs should never be prescribed simply S.O.S. or p.r.n. (pro re nata, 'as occasion arises') without stating for how many times in how many hours or days.

Let us try to learn something from these official hospital inquiries, and the deaths will not be entirely in vain.

\title{
Correspondence
}

\section{Provisions for consent to treatment in the new Mental Health Act}

DeAR SiRS

May I attempt to clarify the questions raised by Ms. Bridgit C. Dimond in her article 'Consent to Treatment by the Mentally Ill and Mentally Handicapped' (Bulletin, August 1983, 7, 145)?

The consent-to-treatment provisions in the Mental Health Act 1983 (Sections 57 and 58) apply to patients detained in hospital for the treatment of mental disorder. Section 57 (psychosurgery and the surgical implantation of hormones to reduce male sexual drive) is extended to informal patients. Section 58 applies to ECT and medicines given after the first three months of continuous detention. Treatments requiring the formalities required by these Sections may not otherwise be given. The exception to this rule is a situation of urgent necessity, when treatments otherwise controlled by Sections 57 and 58 may be given (for the reasons stated in Section 62).

Informal patients and patients on short-term Sections (not at this stage detained for treatment), i.e. Sections 4, 5(2), $5(4), 35,37(4), 135,136$, and conditionally discharged detained patients, do not come within the provisions of Section 58. However, doctors have an ethical and common law duty to give appropriate treatment to any patient (person) in an emergency situation and where it is indicated as a matter of urgent necessity. Any treatment may be given in this situation to save the patient's life, or to prevent a serious deterioration of his condition. A doctor or nurse might even be found to be negligent if he simply stood still and did nothing at all. His duty extends to patients who are informal and those detained under one of the short-term Sections of the Act which contains nothing to abrogate that duty. Section 62 is simply an 'exclusion Section', which removes the restrictions of Sections 57 and 58 allowing some of the treatments to be given to detained patients without formalities as a matter of urgency. Otherwise the common law duty applies.

ROBERT BLUGLASS

Chairman, PPC Working Party on the Mental Health Act All Saints' Hospital

Birmingham

\section{Lord Chancellor's Medical Visitors}

DEAR SIRS

Your readership may be interested to know that the British Medical Association, through my Committee, has been involved in protracted discussions with the Lord Chancellor's Department and the Treasury concerning the remuneration of Lord Chancellor's Medical Visitors in connection with the Court of Protection.

Until February of this year there were three established whole-time posts of Medical Visitor. A change of legislation brought about in 1981 resulted in a reduced workload and a change to part-time appointments. There are currently two Visitors in post with plans to expand the number by at least one in order to reduce the time spent in travelling.

Because the BMA has not yet concluded an agreement which it regards as satisfactory, we must advise Members against applying for one of the new part-time posts until they have first contacted me for further details.

J. R. A. Chawner Chairman, Private Practice Committee

British Medical Association

Tavistock Square, London WCI

\section{Report of the Advisory Council on the Misuse of Drugs}

DeAR SIRS

Debate continues about the recommendations of the DHSS Report of the Advisory Council on the Misuse of Drugs Treatment and Rehabilitation (HMSO, 1982). We believe that the full implementation of the recommendations would be disastrous.

In our Association, 'independent doctor' means a doctor working outside a hospital or drug dependence unit. About half our members are GPs in the NHS and about half are psychiatrists. We believe that independent doctors are now essential to the successful resolution of the country's problems in addiction control.

The subject of drug addiction has become surrounded by mystery and misrepresentation. We believe it should be 'normalized'. Most drug addicts are normal people leading normal lives. Their care should be part of the ordinary daily 
work of GPs and psychiatrists.

I myself am a GP in the NHS. I care for ten addicts. I see them each week, sometimes twice weekly. Of course I receive no payment other than the normal capitation fee of £6 per annum.

As an organization we agree with most of the statements in the DHSS Report, but feel it is too narrow, insufficiently clear and contains too many vague words, phrases, subjective judgments and contradictions. It does nothing to dispel and much to reinforce the myths and misunderstandings that abound in our society about drug addicts. It makes no attempt to assess the country's drug problems as a whole or to assess the black market and the many connections between crime and addiction. We feel that such an assessment is vital before there can be successful treatment and rehabilitation.

The Report points out important problems but does not discuss them. It describes the hopeless inadequacy of the present system, yet goes on to recommend more of the same. It points out that only a minute proportion of addicts attend clinics, but then discusses the problem as though these addicts are the whole problem. It makes no attempt to discuss why the vast majority of addicts (perhaps as many as $95^{\circ}$ per cent) refuse to go to clinics, and it reveals a belief that we cannot share in the effectiveness of committees. It considers neither the needs of stable addicts nor how to help other addicts to become stable. It does not question current prescribing policies, though these have aroused much controversy and dissent. It makes suggestions for the extension of the present licensing system in a way which we believe would cause a considerable increase in crime and distress throughout the community. It fails to discuss the fact that informed opinion is deeply divided about the way in which Britain tackles her drug problem, or the fact that there are totally different, though equally serious, points of view. It makes no criticism of the clinics but much criticism of independent doctors. It makes no mention of the fact that many people believe that it is with GPs at least as much with clinics, that solutions are likely to be found. It tends to invoke planning without any clear statement of what the planning concerns. Overall, it omits so much that a proper balance of emphasis is made impossible.

\section{Our proposals:}

1. There should be an important inquiry into the whole problem of drugs in our society. Until that is done we should be aware of the fact that we do not know what we are trying to control.

2. Boundaries for clinics should be adjusted so that no addict is deprived of a clinic, should he wish to attend one.

3. The prescribing of 'Diconal' should be restricted, but further prescribing restrictions should await greater knowledge.

4. Encouragement and payment should be given to GPs to look after addicts on their lists, and information and training should be easily available to them.

5. Co-operation between independent doctors and clinics should be encouraged by all possible means.

TESSA HARE Secretary

Association of Independent Doctors in Addiction

13 Devonshire Place, London WI

(See also news items on page 195.)

\section{Where are the resources needed the most?}

\section{DeAR Sirs}

Dr Brooks (Bulletin, August 1983, 7, 148) raises important points with implications for the nature and practice of psychiatry in general and community psychiatry in particular. We are preparing a further paper along these lines. Perhaps, however, we could make one or two specific comments.

Establishing the Mental Health Advice Centre gave a community psychiatric base in Lewisham which had previously had none. Monitoring the centre's work from the start soon drew attention to the needs which were being met and those which were not. This led to the development of a Crisis Team based at the Centre whose work has been described (Tufnell $e t a l$ ) and which deals largely with severely ill individuals of the type Dr Brooks mentions. A Rehabilitation Team has been set up at the Centre which will be concerned with psychotic patients and this will be reported upon.

We can assure Dr Brooks that the Mental Health Advice Centre has had catalytic effects on cognate services in Lewisham, including the psychogeriatric service, which is now the responsibility of other consultants whose number is now increased by the first Professor of Psychogeriatrics in the United Kingdom, one of whose tasks will be to improve services in Lewisham.

D. I. BROUGH

N. BOURAS

Lewisham Psychiatric Research Unit

J. P. WATSON

Mental Health Advice Centre

19 Handen Road, London SE12

REFERENCE

TufNell, G., Bouras, N., Brough, D. I., \& Watson, J. P. (1983) Crisis intervention in practice: A three-year study. British Journal of Medical Psychology (submitted for publication).

\section{Insanity and genius}

DeAr SiRs

It would appear your correspondents (Bulletin, March $1983,7,55)$ are not familiar with the literature on the 